\title{
PREVALENCE OF H. PYLORI INFECTION IN A POPULATION FROM THE RURAL AREA OF ARAÇUAÍ, MG, BRAZIL
}

\section{Andreia Maria Rocha de Oliveira, Gifone Aguiar Rocha, Dulciene Maria de Magalhães Queiroz*, Maira Tonidandel Barbosa, Sérgio Caetano Silva}

Laboratório de Pesquisa em Bacteriologia, Faculdade de Medicina, Universidade Federal de Minas Gerais, Belo Horizonte, MG, Brasil

Submitted: August 25, 1998; Returned to authors for corrections: January 18, 1999; April 06, 1999

\section{SHORT COMMUNICATION}

\begin{abstract}
The prevalence of Helicobacter pylori infection was evaluated by ELISA in a rural population in Minas Gerais, Brazil. A total of 114 among 131 adults $(87.0 \%)$ and 54 among 87 children $(62.0 \%)$ presented anti- $H$. pylori antibodies and the prevalence of the infection increased with age $(\mathrm{p}<0.001)$.
\end{abstract}

Key words: $H$. pylori-epidemiology; H. pylori-seroprevalence; H. pylorisocioeconomic level

Helicobacter pylori is a spiral-shaped microaerophilic Gram-negative bacterium that colonises the gastric mucosa of human beings. The microorganism is the major agent of gastritis and plays an important role in the pathogenesis of peptic ulcer and gastric cancer (3).

Current data suggest that the overall prevalence of $H$. pylori infection is higher both in developing countries and in lower socioeconomic groups in the developed world (1). Probably these populations are exposed to conditions that favour the acquisition of the microorganism such as precarious hygiene, crowded household conditions and deficient sanitation.

The aim of this study was to determine the seroprevalence of $H$. pylori infection in a rural population living in the municipality of Araçuaí, Minas
Gerais, and to evaluate the possible risk factors linked to the acquisition of the microorganism.

Araçuaí is a municipality with 33,798 inhabitants (2) located in the Jequitinhonha Valley, Northeastern region of the State of Minas Gerais, distant $680 \mathrm{~km}$ from the state capital. The rural population $(\mathrm{n}=$ 17,257) lives on subsistence agriculture and animal husbandry. The region is considered one of the poorest in Brazil.

The present study was approved by the Ethics Committee of the University Hospital, Federal University of Minas Gerais, Brazil, and informed consent to participate in the study was obtained from the children and from their parents or persons responsible and from the adults.

Serum samples were collected from 218 patients: 131 adults (115 females and 16 males; mean age 37.0

\footnotetext{
* Corresponding author. Mailing address: Laboratório de Pesquisa em Bacteriologia, Faculdade de Medicina, Universidade Federal de Minas Gerais, Av. Alfredo Balena, 190/4026, CEP 30130-100, Belo Horizonte, MG, Brasil. Fax: (+5531)274-2767. E-mail: dqueiroz@medicina.ufmg.br
} 
yrs., range 20 to 78 yrs.) and 87 children and teenagers (53 girls and 34 boys; mean age 13.7 yrs., range 10 to 19 yrs.) residing in the rural area of Araçuaí and attending outpatient clinics linked to the University Hospital.

Data concerning age, sex, use of medication, water supply, sewage, number of rooms in the household, number of persons residing in each dwelling and monthly family income were obtained during interviews with the adults and with parents or persons responsible for the children.

Serum samples were assayed for anti-H. pylori IgG using the Cobas Core anti-H. pylori EIA (Roche Diagnostic Systems, Switzerland) which had been previously validated for Brazilian adults (7) and children over 10 years old (6) in terms of culture, preformed urease test and stained smear, showing $95.4 \%$ and $95.2 \%$ sensitivity and $100 \%$ and $100 \%$ specificity, respectively.

Categorical variables were analysed using the Chisquare test with Yates' correction or the two-tailed Fisher exact test. The linear tendency of the proportions of positivity to anti- $H$. pylori antibodies in different categories of exposure was analysed by the Chi-square test for trends. The level of significance was set at $\mathrm{p}<0.05$.

The annual family income was less than U\$ $3,600.00$ for $92.4 \%$ of the patients studied. The population used untreated water for drinking and cooking and lived in dwellings with no sewer network. The index of crowding (SD), defined by dividing the number of people living in the household by the number of rooms (except bathroom and kitchen), was 1.9 (1.4)

A total of 114 adults $(87.0 \%)$ and $54(62.0 \%)$ children and teenagers presented anti- $H$. pylori antibodies with no significant difference in the prevalence of the infection between adult males and females $(p=1.0)$ or between boys and girls $(p=0.8)$.

The prevalence of $H$. pylori infection increased significantly (Chi-square for trend $=15.9, \mathrm{p}<0.001$ ) with age (Table 1). No association was observed between the rate of infection and annual family income $(p=0.8)$ or between prevalence and crowding $(\mathrm{p}=0.3)$

The results of the present study demonstrate that adults, children and teenagers attending outpatient clinics in a rural area of Araçuaí presented high rates of $H$. pylori infection. It should be noted that the population studied lived in overcrowded homes and had very poor environmental sanitation and water
Table 1 - Seroprevalence of $H$. pylori infection by age in 218 subjects from Araçuaí, Minas Gerais.

\begin{tabular}{ccccc}
\hline $\begin{array}{c}\text { Age } \\
\text { (yr) range }\end{array}$ & Number & $\begin{array}{c}\text { Seropositivity } \\
(\%)\end{array}$ & Odds ratio & CI 95\% \\
\hline $10-19$ & 87 & $54(62.0)$ & 1.00 & - \\
$20-29$ & 49 & $40(81.6)$ & 2.72 & $1.09-6.90$ \\
$30-39$ & 37 & $35(94.5)$ & 10.69 & $2.43-96.30$ \\
$40-49$ & 20 & $18(90.0)$ & 5.50 & $1.18-51.29$ \\
$>50$ & 25 & $21(84.0)$ & 3.21 & $0.95-13.88$ \\
\hline
\end{tabular}

$\mathrm{CI}$, confidence interval; $\mathrm{p}<0.001$

supply, conditions that have been considered important determinants in the acquisition of the microorganism. Similar results were observed by us in a population of the rural area of the State of Mato Grosso with sociodemographic data very similar to those of the present population (8). However, the prevalence of the infection among children was higher than observed in a study of children of low socioeconomic level residing in overcrowded homes in the urban area of Belo Horizonte, Minas Gerais (5). It is likely that the contaminated environment, lack of proper sanitation, and lack of sufficient clean water may explain the difference observed in the prevalence of $H$. pylori infection between these populations since the children of Belo Horizonte used treated city water and had their dwellings served by a sewer network. Other factors that were not investigated in the present study may also account for these differences.

It should be pointed out that most adults studied were females. The reason for this fact is that the serum samples were collected from a predominantly female population of adults attending outpatient clinics. However, several studies have demonstrated that there is no difference in prevalence of $H$. pylori infection between males and females which allows to extrapolate these data to the general population.

The increase in the prevalence of the infection with age observed in the present study is considered by some investigators to be due to a continuous risk of infection throughout life and by others to be due to a cohort effect. It is also possible that, as suggested by Mitchell et al. (4), there are probably two major periods of acquisition of the microorganism in developing countries: the first one in childhood when the chance of infection is quite elevated and the second in adulthood with a small but constant chance of infection.

In conclusion, the prevalence of $H$. pylori 
infection in a rural area of Araçuaí is very high and similar to that observed in other poor regions of Brazil and in other developing countries

The high prevalence of $H$. pylori infection observed in the present study probably reflects the precarious hygiene, the crowded living conditions and the absence of sanitation of this population.

\section{ACKOWLEDGMENTS}

Supported by grants from CNPq, FINEP and FAPEMIG/Brazil

\section{RESUMO}

\section{Prevalência de infecção por $H$. pylori em uma} população da área rural de Araçuaí, MG, Brasil

A prevalência da infecção por Helicobacter pylori foi avaliada em uma população rural de Minas Gerais, Brasil, empregando uma reação de ELISA. Cento e quatorze de 131 adultos $(87,0 \%)$ e 54 de 87 crianças $(62,0 \%)$ apresentaram anticorpos anti-H. pylori. Foi observado aumento da prevalência da infecção com a idade $(\mathrm{p}<0,001)$.

Palavras-chave: $H$. pylori-epidemiologia; $H$. pyloriprevalência; H. pylori-nível sócio-econômico

\section{REFERENCES}

1. Graham, D.Y.; Malaty, H.M.; Evans, D.G.; Evans, D.J.; Kein, P.D.; Adam, E. Epidemiology of Helicobacter pylori infection in an asymptomatic population in the United States. Gastroenterology, 100:1495-1500, 1991.

2. IBGE, Instituto Brasileiro de Geografia e Estatística 1991. Censo Demográfico 1991.

3. McGuigan, J.E. Helicobacter pylori: the versatile pathogen. Dig. Dis., 14:284-303,1996.

4. Mitchell, H.M.; Li, Y.Y.; Hu, P.J.; Liu, Q.; Chen, M.; Du, G.G.; Wang, Z.J.; Lee, A.; Hazell, S.L. Epidemiology of Helicobacter pylori in southern China: identification of early childhood as the critical period for acquisition. J. Infect. Dis., 166:149-153,1992.

5. Oliveira, A.M.R.; Queiroz, D.M.M.; Rocha, G.A.; Mendes, E.N. Seroprevalence of Helicobacter pylori in children of low socioeconomic level in Belo Horizonte, Brazil. Am. J. Gastroenterol., 89:2201-2204, 1994.

6. Queiroz, D.M.M.; Rocha, G.A.; Oliveira, A.M.R.; Mendes, E.N.; Moura, S.B.; Fulgêncio, S.H.G.; Carvalho, A.S.T.; Oliveira, C.A. Children present a lower value of cutoff than adults in a 2 nd generation ELISA test for the diagnosis of $H$. pylori infection. Rev. Bras. Med., 53 (supl):40, 1996.

7. Rocha, G.A.; Oliveira, A.M.R.; Queiroz, D.M.M.; Mendes, E.N.; Moura, S.B.; Oliveira, C.A.; Ferrari, T.C.A. Diagnosis of Helicobacter pylori infection by Cobas Core ELISA in adults from Minas Gerais, Brazil. Brazilian J. Med. Biol. Res., 31:1263$1268,1998$.

8. Souto, F.J.D.; Fontes, C.J.F.; Rocha, G.A.; Oliveira, A.M.R.; Mendes, E.N.; Queiroz, D.M.M. Prevalence of Helicobacter pylori infection in a rural area of the State of Mato Grosso, Brazil. Mem. Inst. Oswaldo Cruz, 93:171-174, 1998. 